\title{
Polyostotic Fibrous Dysplasia with Raised Steroid Excretion
}

\author{
F. W. ALEXANDER \\ From The Hospital for Sick Children, Great Ormond Street, and the Institute of Child Health, Guilford Street, Lundon
}

\begin{abstract}
Alexander, F. W. (1971). Archives of Disease in Childhood, 46, 90. Polyostotic fibrous dysplasia with raised steroid excretion. Four female patients with polyostotic fibrous dysplasia and sexual precocity are presented in detail. Two of the patients suffered spontaneous fracture of the femur.

Steroid excretion was raised in 3 out of the $\mathbf{4}$ girls, but excretion of total urinary gonadotrophins was normal in 2 of them.
\end{abstract}

The syndrome of fibrous dysplasia of bone, sexual precocity, and skin pigmentation was first described by McCune in 1936. This was corroborated by Albright et al. (1937) in the next year, when they described 4 more females with sexual precocity and 1 male with no such precocity. The syndrome was defended as an entity and became variously known as McCune-Albright's syndrome, Albright's syndrome, or polyostotic fibrous dysplasia.

Since that time a further 51 case reports have been published (Falconer and Cope, 1942; Harris, Dudley, and Barry, 1962; Benedict, 1962, 1966; Harris, 1967; Aarskog and Tveteraas, 1968; Zangeneh, Lulejian, and Steiner, 1966; Husband and Snodgrass, 1970). The fibrous dysplasia has been the invariable feature of this condition; only half the girls have presented with sexual precocity; the skin pigmentation, though found frequently, has not always been present at birth.

Two patients with fibrous dysplasia, attending this hospital, were admitted, in quick succession, with femoral fractures. Both patients had had pain in the leg for some months. 2 further cases were found in the records and all 4 patients are presented in detail. In view of the dearth of published information about the urinary excretion of steroids and gonadotrophins in these children, they are reported in full.

\section{Case Reports}

Case 1. This girl was the third child of unrelated parents who presented at the age of 5 years. Her perinatal history and subsequent milestones were normal. Extensive birthmarks were noted at the age of

Received 16 June 1970.
6 weeks. Pubic hair appeared at 4 years and breast enlargement one month before presenting to the hospital. This was followed, two weeks later, by vaginal bleeding which lasted for 10 days.

On examination (see Fig. 1) her height was on the 50 th centile, her weight on the 75th centile. There were extensive pigmented patches over the left arm, left and right chest, and right leg, crossing the midline. Her breasts were enlarged-Stage III (Tanner and Whitehouse, 1959) as were her clitoris and both labia. Pubic hair was present-Stage II (Tanner scale). The vaginal mucosa was bluish and a 'small adult' cervix was palpable per rectum.

Investigations. Serum calcium and phosphorus were $9.9 \mathrm{mg} / 100 \mathrm{ml}$ and $5.2 \mathrm{mg} / 100 \mathrm{ml}$, respectively. The alkaline phosphatase was raised to 34 King Armstrong units (KA). The output of 17 ketosteroids (17 oxosteroids, $17 \mathrm{KS}$ ) at $1.9 \mathrm{mg} / 24 \mathrm{hr}$ was high for her age (Prout and Snaith, 1958) and an excretion of $15 \mathrm{mg} /$ $24 \mathrm{hr}$ for total 17-hydroxycorticoids (17 OCHS) represents a level four times the upper limit of normal for surface area (Clayton, Edwards, and Renwick, 1963). $X$-rays of the skull showed no abnormality and those of the skeleton were first reported as normal but in retrospect showed early cystic changes (in the tibiae and left fibula) characteristic of fibrous dysplasia. Her bone age was advanced to 6.5 years. A pneumoencephalogram failed to show any abnormality and an examination under anaesthetic was normal apart from an 'adult' uterus. A vaginal smear was well oestrogenized.

Progress. She was given 6-medroxyprogesterone (Depot Provera-Upjohn Ltd) $150 \mathrm{mg}$ intramuscularly every two weeks initially, later reduced to once a month. She had no further vaginal bleeding, though her pubic hair became more abundant. She remained well until she developed pain in the left leg two years later. $X$-rays showed extensive cystic changes in the neck and shaft of 


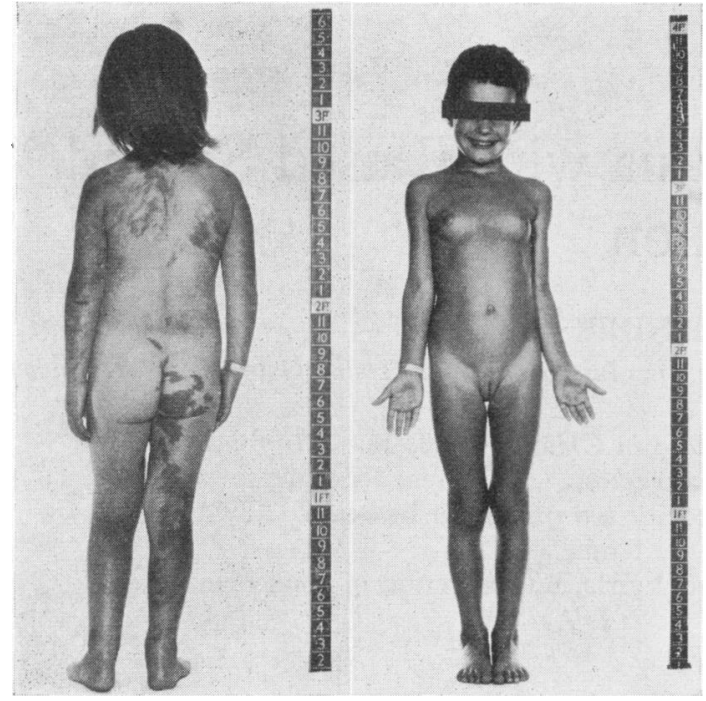

FIG. 1.-Rear view of Case 1 to show the degree of pigmentation.

FIG. 2.-Front view of Case 3 to show typical sexual precocity.

both femora, and her bone age was then 8 years (chronological age 6.7 years). One year after this she began to limp on the left leg. On examination, there was limitation of external and internal rotation of that hip because of pain; the great trochanter was more easily palpable on that side but there was no shortening.

The recent diagnosis of a fracture in Case 3 prompted tomography of the neck of the left femur which revealed a crack through the cortex of the bone into a large cyst. The neck was therefore fixed with a Dewett nail and plate and strengthened with bone chips. She has made satisfactory progress to the time of writing.

Case 2. This second female child born to unrelated parents had vaginal bleeding at the age of 6 weeks, lasting for 4 days. This recurred at 6,12 , and 18 months, lasting for 8 days. Her birth and development were normal.

On examination at 18 months there was no secondary sexual development and no pigmentation.

Investigations. An $x$-ray of the skull was normal. The output of $17 \mathrm{KS}$ at $1.8 \mathrm{mg} / 24 \mathrm{hr}$ was high (Prout and Snaith, 1958). She was examined under anaesthesia and a small cystic tumour was felt. This was confirmed at laparotomy to be a cyst of the right ovary, which was excised. The left ovary and the right adrenal gland were noted to be normal.

By the age of 20 months, there had been further vaginal bleeding and development of the breasts. At 3․ㅡㄹ years her height and weight were above the 90th centile, her breast enlargement Stage II (Tanner scale), and her bone age 5 years.
At $3 \frac{1}{2}$ years, the output of $17 \mathrm{KS}$ at $0.8 \mathrm{mg} / 24 \mathrm{hr}$ was at the upper limit of normal for her age, that of $17 \mathrm{OHCS}$ at $2 \cdot 7 \mathrm{mg} / 24 \mathrm{hr}$ was high for her surface area. Excretion of total urinary gonadotrophins (TUG) by bioassay estimated on two occasions, was found to be less than $0.5 \mathrm{HMG} 20 \mathrm{~A}^{\star}$ units $/ 24 \mathrm{hr}$ which is within normal limits (Fitschen and Clayton, 1965).

Further estimations at the age of 7 years confirmed the normal TUG excretion and a raised $17 \mathrm{KS}$ output of $4 \cdot 2 \mathrm{mg} / 24 \mathrm{hr}$. A skull $x$-ray showed thickening of the basi-sphenoid including the sella turcica; examination under an anaesthetic was normal

Progress. 6-medroxyprogesterone was begun at 9 years because of persistent vaginal bleeding, but as this failed to control the bleeding and in view of her skeletal maturity and emotional distress with the injections, they were discontinued.

At the time of writing her bone age is still advanced; her epiphyses are almost fused. Her height and weight are on the 75th centile and she is menstruating regularly. A recent skull $x$-ray showed progression of the cystic changes in the basi-sphenoid.

Case 3. This girl, the first child of healthy unrelated parents, was noticed to have breast enlargement at the age of 1 year, followed by vaginal bleeding at 21 months. Her perinatal history and milestones were otherwise normal. Further bleeding occurred every 6 months, together with temporary breast enlargement.

On examination (at $5 \frac{1}{2}$ years, see Fig. 2) her height and weight were above the 90 th centile. Her breasts were enlarged-Stage III (Tanner Scale) and pubic hair was present-Stage II (Tanner). There was also enlargement of the labia majora. A small brown 'tache' was present over the centre of the back.

Investigations. Serum calcium and phosphorus were $9.8 \mathrm{mg} / 100 \mathrm{ml}$ and $3.7 \mathrm{mg} / 100 \mathrm{ml}$, respectively. The alkaline phosphatase was raised at $36 \mathrm{KA}$ units. The output of $17 \mathrm{KS}$ and $17 \mathrm{OHCS}$ at $0.2 \mathrm{mg} / 24 \mathrm{hr}$ and $2.0 \mathrm{mg} / 24 \mathrm{hr}$, respectively, was normal. The excretion of TUG at $0.39 \mathrm{mg}$. IRP/24 hr was also normal. A vaginal smear was well oestrogenized, and skull $x$-rays and EEG were both normal.

Progress. She was given 6-medroxyprogesterone, $150 \mathrm{mg}$ intramuscularly two-weekly initially and had no further vaginal bleeding. Her breasts decreased in size but her pubic hair became more abundant. One year later she complained of pain in the left leg and then developed a limp.

On examination, there was pain at the limit of all movement, but no shortening. There was, however, some reduction in circumference of the left leg.

A skeletal survey showed extensive cystic changes in

*HMG 20A is the reference number of Human Menopausal Gonadotrophin used in Department of Chemical Pathology at time tests were made. Relative potency between HMG and International Reference Preparation is given by Fitschen and Clayton (1965). 
the entire left side of the skeleton but not involving the skull. There was a large cyst in the neck of the left femur and tomograms of this area showed that there had been a fracture through the cortex of the bone into the cyst. The femoral neck was, therefore, curetted out and fixed with a Dewitt nail and plate. She made a good recovery after operation but has since fallen and fractured the left leg below the level of the plate.

Case 4. The second child of British parents was born at 38 weeks after a medical induction. There were no neonatal problems but pigmentation was seen over the lower back at birth and some pubic hair appeared at 3 months. Vaginal bleeding started at 4 weeks of age; it recurred one month later for 3 days, then at $1 \frac{1}{2}$ years and 1 year 7 months for 7 days. Breast enlargement was noticed at $1 \frac{1}{2}$ years.

On examination (at 2 years) her height was on the 75th centile, her weight on the 50th centile. Her breasts were developed Stage II (Tanner), pubic hair was present, and there was some enlargement of both labia. Areas of pigmentation were noted over the right abdomen, loin, and over the sacrum, crossing the midline.

Investigations. Serum calcium and phosphorus were normal $(9.8 \mathrm{mg} / 100 \mathrm{ml}$ and $6.0 \mathrm{mg} / 100 \mathrm{ml}$, respectively) as was the alkaline phosphatase (15 KA units). The output of $17 \mathrm{KS}$ was raised at $0.9 \mathrm{mg} / 24 \mathrm{hr}$, that of 17 OHCS was also raised at $2 \cdot 10 \mathrm{mg} / 24 \mathrm{hr}$. Skeletal survey showed fibrous dysplasia in both femora, the left ileum, and fibula, but not in the skull.

Progress. Since that time she has continued to have one episode of vaginal bleeding per year (insufficient to warrant the use of 6-medroxyprogesterone). There has been some progression of the dysplasia in the right femur with wasting of the right thigh muscles, but no pain or limp on that side.

\section{Discussion}

The syndrome as it was originally described by McCune (1936) and Albright et al. (1937) was considered to be an entity for a number of years. It was thought that the sexual precocity only occurred in girls. Falconer and Cope (1942) however described a boy with fibrous dysplasia and sexual precocity, and a girl with no sexual precocity, and so advocated a broader view of the condition with fibrous dysplasia as its essential feature. They stated that the fibrous dysplasia became stationary in adult life and that it was never fatal. Harris et al. (1962) painted a much gloomier picture when analysing the progress of 37 cases with fibrous dysplasia. $70 \%$ of patients presented with a limp, leg pain, or fracture. The commonest physical deformity, occurring in $60 \%$, was leg length discrepancy. They found that $85 \%$ had suffered one fracture and $40 \%$ had suffered 3 or more fractures (though one patient with two-thirds of the skeleton involved had never suffered a fracture in 67 years of active life). There was no evidence that the condition became stationary after puberty, and there were three deaths either from inanition following multiple fractures, or from pneumonia following fracture of a number of ribs. Five more patients were living a wheelchair existence. Harris et al. (1962) emphasized that the more extensive the fibrous dysplasia at the onset of the disease, the more rapid its progression and the worse the deformities.

The femur was involved in $92 \%$ of cases, the tibia in $81 \%$. Thus an $x$-ray of the lower limbs is the single most helpful diagnostic investigation. This fact is borne out in the present series, and any patient with fibrous dysplasia who develops pain in the leg or a limp should have detailed $x$-ray studies to exclude a pathological fracture.

The features of sexual precocity are well described, and vaginal bleeding may occur well in advance of breast enlargement (Benedict, 1962). In this series vaginal bleeding started, in Cases 2 and 4, at a much younger age than previously reported.

The earliest reports of fibrous dysplasia did not include hormone assays as they were not readily available. Benedict (1962) reviewing 38 cases found only two estimations of $17 \mathrm{KS}$ excretion, both of which were normal. In a further report (Benedict, 1966) on a boy with active spermatogenesis and sexual precocity, the output was significantly raised. Harris (1967) describes a girl with fibrous dysplasia whose output of $17 \mathrm{KS}$ and $17 \mathrm{OHCS}$ was raised on two occasions. Of the 4 girls in this series, only 1 (Case 3) has an output of $17 \mathrm{KS}$ and 17 OHCS within normal limits (Prout and Snaith, 1958; Clayton et al., 1963) the 4 estimations on the 3 other girls are well outside the normal range.

These raised values support Benedict's original suggestion (Benedict, 1962), that the sexual precocity, without evidence of ovulation, is due to premature activity of the adrenal cortex-a premature 'adrenarche'. However, it is difficult to reconcile this proposition with a recent report by Aarskog and Tveteraas (1968) of a girl who underwent bilateral total adrenalectomy for Cushing's syndrome, at the age of 4 months and who developed, over the next 4 years, fibrous dysplasia, skin pigmentation, and sexual precocity, but without evidence of a pituitary tumour.

One of the causes of the condition originally put forward by McCune and Albright was premature release of gonadotrophins from the anterior pituitary. Bony changes at the base of the skull were thought to be the initiating factor, but in Harris's series (Harris et al., 1962) the skull was 
involved only in $50 \%$ of cases and in the present series only 1 out of 4 patients had such involvement.

Gonadotrophin excretion has been determined in only a few cases (Benedict, 1966) and low values have been found. Excretion of TUG on 4 occasions in 2 of the girls in this series was within normal limits (all 4 estimations of excretion of TUG were performed before starting 6-medroxyprogesterone). Harris (1967) reports a single raised level for follicle stimulating hormone but this was not reproducible 5 years later. Recently, Husband and Snodgrass (1970) have reported the measurement of excretion of TUG over a 10-day period. They found that the levels were raised conspicuously on two occasions only during that period. However, their peaks were not followed by vaginal bleeding, and as other parameters for ovulation (such as body temperature and urinary pregnanediol excretion) were not measured in parallel, no further significance can be attached to these findings. There is no doubt that patients with this condition may subsequently be fertile (Albright et al., 1937), but there has never been documented evidence for ovulation in the few patients coming to laparotomy (Harris, 1967).

There was no clinical evidence in this series of any associated hyperthyroidism, as has been a feature of previous reports (Benedict, 1966; Zangeneh et al., 1966).

I should like to thank Dr. G. H. Newns for his advice and permission to report three of the cases, Professor Barbara E. Clayton for her helpful criticism and for the biochemical investigations, and Dr. A. P. Norman for permission to report one of the cases.

\section{REFERENCES}

Aarskog, D., and Tveteraas, E. (1968). McCune-Albright's syndrome following adrenalectomy for Cushing's syndrome in infancy. Fournal of Pediatrics, 73, 89.

Albright, F., Butler, A. M., Hampton, A. O., and Smith, P. (1937) Syndrome characterized by osteitis fibrosa disseminata, areas of pigmentation and endocrine dysfunction, with precocious puberty in females. New England fournal of Medicine, 216, 727.

Benedict, P. H. (1962). Endocrine features in Albright's syndrome (fibrous dysplasia of bone). Metabolism, 11, 30 .

Benedict, P. H. (1966). Sex precocity and polyostotic fibrous dysplasia: report of a case in a boy with testicular biopsy. American Fournal of Diseases of Children, 111, 426.

Clayton, B. E., Edwards, R. W. H., and Renwick, A. G. C. (1963). Adrenal function in children. Archives of Disease in Childhood, $38,49$.

Falconer, M. A., and Cope, C. L. (1942). Fibrous dysplasia of bone with endocrine disorders and cutaneous pigmentation(Albright's disease). Quarterly fournal of Medicine, 11, 121.

Fitschen, W., and Clayton, B. E. (1965). Urinary excretion of gonadotrophins with particular reference to children. Archives of Disease in Childhood, 40, 16.

Harris, F. (1967). Polyostotic fibrous dysplasia with a high FSH. Proceedings of the Royal Society of Medicine, 60, 11 .

Harris, W. H., Dudley, H. R., Jr., and Barry, R. J. (1962). The natural history of fibrous dysplasia. Fournal of Bone and foint Surgery, 44A, 207.

Husband, P., and Snodgrass, G. J. A. I. (1970). McCune-Albright syndrome with endocrinological investigations. American fournal of Diseases of Children, 119, 164.

McCune, D. J. (1936). Osteitis fibrosa cystica: the case of a nine year old girl who also exhibits precocious puberty, multiple pigmentation of the skin and hyperthyroidism. American fournal of Diseases of Children, 52, 743.

Prout, M., and Snaith, A. H. (1958). Urinary excretion of 17-ketosteroids in children. Archives of Disease in Childhood, 33, 301.

Tanner, J. M., and Whitehouse, R. H. (1959). Data prepared for Great Ormond Street Growth and Development Charts.

Zangeneh, F., Lulejian, G. A., and Steiner, M. M. (1966). McCuneAlbright syndrome with hyperthyroidism, American fournal of Diseases of Children, 111, 644.

Correspondence to Dr. F. W. Alexander, Heavy Metais Laboratory, Institute of Child Health, 30 Guilford Street, London W.C.1. 